\title{
Brain metastases in Asian HER2-positive breast cancer patients: anti-HER2 treatments and their impact on survival
}

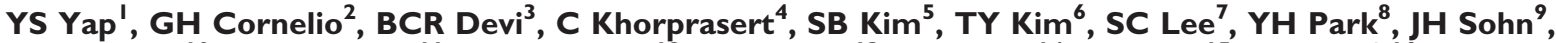

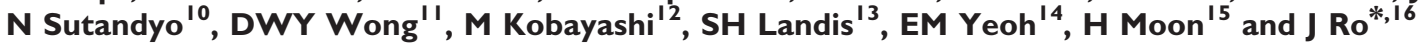

'Department of Medical Oncology, National Cancer Centre Singapore, II Hospital Drive, Singapore 1696 I0, Singapore; 'Saint Peregrine Oncology Unit, San Juan de Dios Hospital, 2772 Roxas Boulevard, Pasay City 1300, Philippines; ${ }^{3}$ Department of Radiotherapy, Oncology and Palliative Care, Sarawak General Hospital, Kuching 93586, Malaysia; ${ }^{4}$ Division of Radiation Oncology, Faculty of Medicine, Chulalongkorn University, Rama 4 Road, Bangkok 10330, Thailand; ${ }^{5}$ Asan Medical Center, University of Ulsan College of Medicine, 88 Olympic-ro 43-gil, Songpa-gu, Seoul 138-736, Korea; ${ }^{6}$ Seoul National University Hospital, 101 Daehak-ro, Jongno-gu, Seoul II 0-744, Korea; ${ }^{7}$ Department of Haematology-Oncology, National University Health System, IE Kent Ridge Road, Singapore 1 19228, Singapore; ${ }^{8}$ Samsung Medical Center, 50 Irwon-dong, Gangnam-gu, Seoul I 35-7I 0, Korea; ${ }^{9}$ Severance Hospital, Yonsei University Health System, 50 Yonsei-ro, Seodaemun-gu, Seoul 120-752, Korea; ${ }^{10}$ Dharmais Hospital National Cancer Center, Jl. Let. Jend. S. Parman Kav. 84-86, Slipi, Jakarta Barat II420, Indonesia; "Faculty of Medicine, University of Malaya, Kuala Lumpur 50603, Malaysia; ${ }^{12}$ GlaxoSmithKline, 5 Moore Drive 17.21 36K.2A, Research Triangle Park, NC 27709, USA; ${ }^{13}$ European Medical Affairs, GlaxoSmithKline, I-3 Iron Bridge Road, Uxbridge, Middlesex UB I I IBT, UK; ${ }^{14}$ Oncology R\&D, GlaxoSmithKline Pte Ltd, I 50 Beach Road, Gateway West, Singapore I89720, Singapore; ${ }^{15}$ GlaxoSmithKline (China) R\&D Co. Ltd, 917 Halei Road, Zhangjiang Hi-Tech Park, Pudong, Shanghai 201203, China; ${ }^{16}$ National Cancer Center, III Jeongbalsanro, Ilsan-gu, Goyang-si, Gyeonggi-do 4I 0-769, Korea

BACKGROUND: In Asia, large-scale studies on anti-HER2 treatment in HER2-positive breast cancer patients with brain metastases are limited. We studied the treatment patterns of these patients in Asia to evaluate the impact of anti-HER2 treatment on the time to occurrence of brain metastases (TTBM) and survival after brain metastasis (BM).

METHODS: A retrospective study of HER2-positive breast cancer patients diagnosed with BM between January 2006 and December 2008 in six Asian countries was conducted. Demographics, tumour characteristics, treatment details, and events dates were collected from medical records.

RESULTS: Data from 280 patients were analysed. Before BM, 63\% received anti-HER2 treatment. These patients had significantly longer TTBM than those without anti-HER2 treatment (median 33 vs 19 months; $P<0.002$ ). After BM, 93\% received radiotherapy, 57\% received chemotherapy, and $41 \%$ received anti-HER2 treatment (trastuzumab and/or lapatinib). Use of both anti-HER2 agents, primarily sequentially, after BM demonstrated the longest survival after BM and was associated with a significant survival benefit over no anti-HER2 treatment (median 26 vs 6 months; hazard ratio 0.37; 95\% Cl 0.19-0.72).

CONCLUSION: Anti-HER2 treatment before BM was associated with longer TTBM. Anti-HER2 treatment after BM was associated with a survival benefit, especially when both trastuzumab and lapatinib were utilised.

British Journal of Cancer (2012) I 07, I075-1082. doi:I0.1038/bjc.2012.346 www.bjcancer.com

Published online 23 August 2012

(c) 2012 Cancer Research UK

Keywords: Asian; HER2-positive breast cancer; brain metastases; lapatinib; trastuzumab; survival

Brain metastases are associated with substantial morbidity and mortality in cancer (DiStefano et al, 1979). The incidence of metastases to the brain is particularly high in patients with human epidermal growth factor receptor 2 (HER2 or ErbB2)-positive breast cancer (Bendell et al, 2003; Clayton et al, 2004; Shmueli et al, 2004; Stemmler et al, 2006; Park et al, 2009a).

Trastuzumab-based treatment is regarded as standard treatment of care for HER2-positive breast cancer because of its proven survival benefits (Slamon et al, 2001; Vogel et al, 2002). Trastuzumab-based treatment has also been shown to delay the development of brain metastases (Dawood et al, 2008; Park et al, $2009 b)$. However, consensus guidelines on systemic treatment after the development of brain metastasis (BM) in HER2-positive breast

*Correspondence: Dr J Ro; E-mail: jungsro@ncc.re.kr

Received I4 March 20 I2; revised 10 July 2012; accepted I3 July 20 I2; published online 23 August 2012 cancer are limited (NCCN, 2011). Published studies on the effect of trastuzumab-based treatment on survival after BM reported mixed results. Although some studies demonstrated significant survival benefit (Bartsch et al, 2007; Park et al, 2009b; Le Scodan et al, 2011), another study showed no significant benefit after having adjusted for confounders (Dawood et al, 2008). The observed survival benefit may also be attributed to better control of extracranial disease rather than BM, as trastuzumab penetrates the blood-brain barrier poorly (Pestalozzi and Brignoli, 2000; Altundag et al, 2005).

These findings highlight the need for new therapeutic approaches to effectively prevent or treat brain metastases in HER2-positive breast cancer patients. Lapatinib, a small-molecule, dual HER-1/HER-2 inhibitor, which can potentially cross the blood-brain barrier, has shown promising effects on brain metastases in both preclinical and clinical settings. In preclinical models, lapatinib showed activity in inhibiting BM and reducing the number of large HER2-transfected brain metastases (Gril et al, 2008). In clinical studies, lapatinib was effective in volumetric 
reduction of brain lesions as monotherapy (Lin et al, 2008; Lin et al, 2009) and in combination with capecitabine (Boccardo et al, 2008; Lin et al, 2009; Ro et al, 2010; Sutherland et al, 2010; Bachelot et al, 2011; Lin et al, 2011). Lapatinib and capecitabine combination therapy was also effective in reducing BM as the first site of recurrence (Cameron et al, 2008). More recently, a few observational studies have demonstrated positive impact on survival in limited numbers of HER2-positive breast cancer patients treated with lapatinib alone (Park et al, 2009a) or in combination with trastuzumab and chemotherapy (Metro et al, 2011; Bartsch et al, 2012) after BM.

To date, most observational studies on HER2-positive breast cancer patients with brain metastases have investigated the use of trastuzumab only, primarily in Western populations (Stemmler et al, 2006; Yau et al, 2006; Bartsch et al, 2007; Lichinitser et al, 2007; Dawood et al, 2008; Niwinska et al, 2010). In Asia, there is a paucity of large-scale studies on anti-HER2 treatment in HER2positive breast cancer patients with brain metastases and its impact on BM-related outcomes in 'real world' clinical practice. We conducted a multicentre, retrospective study of HER2-positive breast cancer patients diagnosed with BM in six Asian countries. This report aims to: (i) describe the current treatment paradigm for brain metastases in HER2-positive breast cancer patients in Asia, with specific focus on the use of anti-HER2 treatment; and (ii) understand the potential clinical role of anti-HER2 treatments on time to BM as well as survival after the development of brain metastases.

\section{PATIENTS AND METHODS}

\section{Study design and population}

In this retrospective observational study, consecutive female HER2-positive breast cancer patients diagnosed with BM between January 2006 and December 2008 were identified from hospital medical records and databases in 23 medical centres in six Asian countries (Indonesia, Korea, Malaysia, Philippines, Singapore, and Thailand). Women who had leptomeningeal metastases only or another primary cancer diagnosed between the time of diagnosis of breast cancer and brain were excluded from this study.

HER2 positivity was defined as either HER2 immunohistochemistry (IHC) $3+$ staining or positive HER2 fluorescence in situ hybridisation (FISH). Brain metastases were diagnosed by computed tomography and/or magnetic resonance imaging with neurological signs and symptoms.

Patient demographics, tumour characteristics at diagnosis, dates of metastatic events, treatment details, and survival status were abstracted from medical records. All patients were followed until either the date of death or the last-known physician visit on or before 30 June 2009. This study was approved by all local institutional review boards.

\section{Statistical methods}

Patient demographics and tumour characteristics were summarised overall and by receipt of anti-HER2 treatment after BM. Comparisons between groups used the $\chi^{2}$, Fisher's exact or Kruskall-Wallis test, where appropriate.

Time to occurrence of brain metastases (TTBM) was defined as the time from initial diagnosis of HER2-positive breast cancer to the diagnosis of BM. Brain as first site of metastasis was defined as the presence of brain metastases in the absence of other synchronous metastases. Overall survival (OS) after BM was defined as the time from diagnosis of BM to death (event) or last follow-up visit (censor).

Kaplan-Meier estimates of median TTBM overall and stratified by anti-HER 2 treatment before BM were calculated and compared using the log-rank test. As there were insufficient numbers of patients treated with individual anti-HER2 treatments before BM diagnosis, exposure before BM was reported as a binary variable (any or no anti-HER2 treatment). Brain as first site of metastasis was stratified by receipt of anti-HER2 treatment in the adjuvant setting and compared using the $\chi^{2}$ test. As trastuzumab alone was the only anti-HER2 treatment received in the adjuvant setting, exposure in the adjuvant setting was reported as a binary variable (adjuvant trastuzumab or no adjuvant trastuzumab treatment).

Median OS after BM was also estimated by Kaplan-Meier method and compared using the log-rank test. Exposure to antiHER2 treatment after BM was reported both as a binary variable (any or no anti-HER2 treatment) and as a detailed variable that separated patients into those who received either trastuzumab alone, lapatinib alone, both agents or no anti-HER2 treatment. Patients in the 'both agents' category may have received the antiHER2 agents either sequentially or concomitantly.

Univariate and multivariate Cox regression analyses were performed to identify independent predictors of OS after BM. Adjusted Cox proportional hazard models were also developed to estimate the association between anti-HER2 treatment received after BM and OS after BM. Potential confounding variables that were significantly associated with both the likelihood of receiving anti-HER2 treatment after BM and with OS after BM were entered into a backward selection model, which retained only those variables significant with a $P$-value of $\leqslant 0.05$.

Sensitivity analyses of the final fully adjusted model were conducted to explore the robustness of the adjusted hazard ratios (HRs). The adjusted Cox proportional hazard models were refitted after having relaxed the proportional hazards assumption for key confounders (chemotherapy and hormonal therapy after BM) that may have a time-dependent effect on OS after BM.

\section{RESULTS}

\section{Patient demographics and characteristics}

A total of 311 patients were initially identified as potential study candidates; 31 patients were subsequently excluded either due to lack of information on HER2 testing or due to lack of FISH confirmation for tumours graded $2+$ by IHC. The remaining 280 patients with confirmed HER2-postive breast cancer were included in this final analysis (Figure 1). Among these 280 patients, 239 were graded $3+$ by IHC with or without confirmatory FISH, 21 were graded $2+$ by IHC with FISH confirmation, and 20 were graded FISH-positive alone.

Approximately one-half $(48.9 \%)$ of the patients came from Korea, while $25.4 \%, 13.6 \%, 9.6 \%, 1.8 \%$, and $0.7 \%$ were from Singapore, Thailand, Malaysia, Indonesia, and Philippines, respectively. The majority of patients $(75.7 \%)$ were treated in public medical centres.

Table 1 shows the demographics and clinical features at diagnosis of breast cancer and BM in the analysed population and in different anti-HER2 treatment groups. The median age at diagnosis of BM was 52 years. Three-quarters $(76.8 \%)$ of patients had multiple brain lesions and $10.7 \%$ had leptomeningeal seeding. Apart from differences in frequency of various histological types and nuclear grades of primary breast cancer, and leptomeningeal seeding, the treatment groups were well balanced with regards to other characteristics.

\section{Treatment patterns}

Tables 2 and 3 show the treatments received before and after BM. Seven $(2.5 \%)$ patients did not receive any treatment for $\mathrm{BM}$ (Table 2). Radiotherapy (92.9\%) and chemotherapy (57.1\%) were the most common treatment modalities received after diagnosis of BM. 


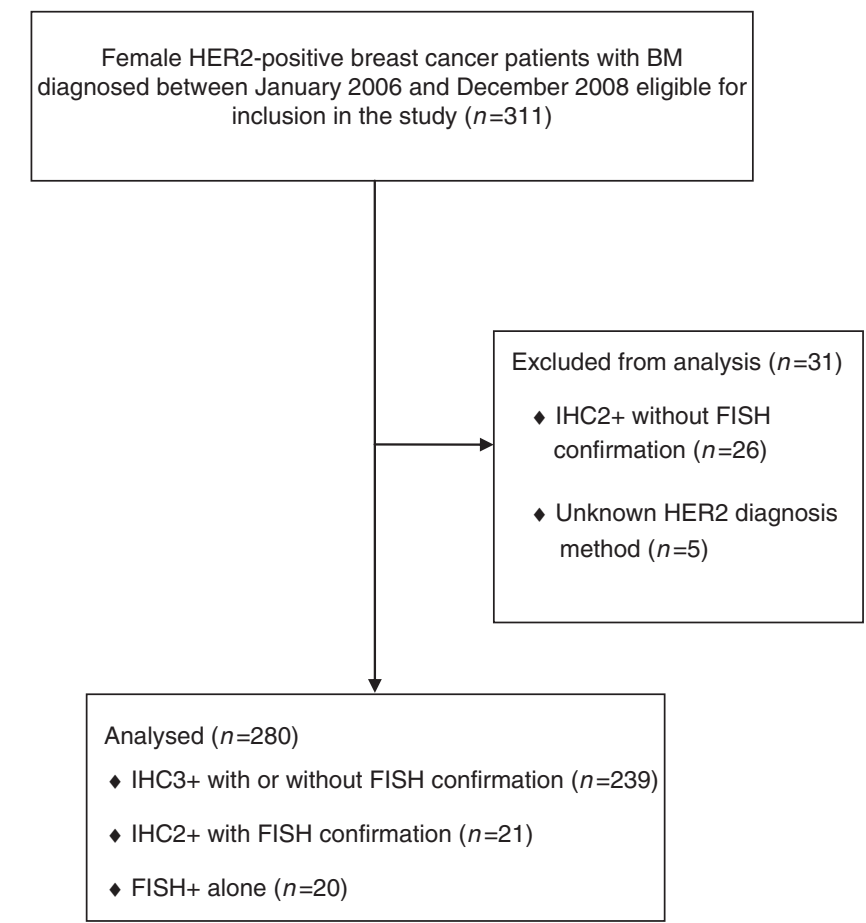

Figure I Patient cohort. FISH, fluorescence in situ hybridisation; IHC, immunohistochemistry.

Sequential radiotherapy and chemotherapy was the most common treatment $(54.6 \%)$ received after BM.

Anti-HER2 treatment was utilised in $62.9 \%$ of patients before $\mathrm{BM}$ and in $40.7 \%$ of patients after presentation with brain metastases (Table 2). Anti-HER2 treatment before diagnosis of BM was primarily trastuzumab alone $(86.9 \%$; 153 of 176$)$ administered in the adjuvant $(n=28)$ and/or metastatic setting $(n=131)$ (Table 3$)$. After the diagnosis of BM, trastuzumab alone was still the most common anti-HER2 treatment received $(49.1 \%$; 56 of 114$)$, followed by lapatinib alone $(26.3 \% ; 30$ of 114$)$ and lapatinib in combination with trastuzumab $(24.6 \% ; 28$ of 114$)$. Among the 28 patients who received both anti-HER2 agents after $\mathrm{BM}$, trastuzumab and lapatinib were primarily given sequentially in 22 patients $(78.6 \%) ; 6$ patients $(21.4 \%)$ received both drugs concomitantly. Anti-HER2 treatment was commonly given in combination with radiotherapy $(93.0 \% ; 106$ of 114$)$ or radiotherapy and chemotherapy (80.7\%; 92 of 114$)$.

\section{Time to brain metastasis (TTBM) and timing of brain metastasis $(\mathrm{BM})$}

The median TTBM was 30.1 months (95\% CI 25.0-32.7) for all patients. BM occurred significantly later in patients who received anti-HER2 treatment before BM (median TTBM 33.2 months; $95 \%$ CI 31.6-35.8) compared with those who did not (19.1 months; $95 \%$ CI 15.4-24.9; $P=0.002$ ) (Supplementary Table 1). Brain was the first site of metastasis in $62(22.2 \%)$ patients. Patients who received adjuvant trastuzumab were more likely to present with brain as the first site of metastasis than those who did not $(46.4 \% ; n=13$ vs $19.5 \% ; n=49 ; P=0.003)$.

\section{Overall survival (OS) after brain metastasis (BM)}

At the end of the study period, $61.8 \%(n=173)$ had died, of which $54.9 \%(n=95)$ died due to complications of brain metastases. The median OS after BM was 10.9 months (95\% CI 9.0-11.9) for all patients. OS after BM was significantly longer in patients who received anti-HER2 treatment after BM than those who did not (median 18.5 vs 5.7 months; $P<0.001$; Figure 2A). The greatest survival benefit (25.9 months) was observed in patients who received both trastuzumab and lapatinib, followed by lapatinib alone (21.4 months), trastuzumab alone (10.5 months), and without anti-HER2 treatment $(5.7$ months $)(P<0.001)$ (Figure $2 \mathrm{~B})$.

Table 4 summarises the results of Cox regression analyses for independent prognostic factors for OS after BM. Older age at BM diagnosis, multiple brain metastases lesions, and leptomeningeal seeding were associated with poorer survival, whereas premenopausal status, and receipt of chemotherapy, hormonal therapy or anti-HER2 treatment after BM were predictors of prolonged survival. Of note, receipt of anti-HER2 treatment before diagnosis of BM was not significantly associated with improved OS after BM. In multivariate analysis, after controlling for age at BM, number of brain metastases lesions, receipt of chemotherapy, and receipt of hormonal therapy after BM, anti-HER2 treatment after BM remained significantly associated with improved OS after BM (38\% reduction in risk of death compared with no anti-HER2 treatment; HR, 0.62; 95\% CI 0.43-0.89) (Table 4).

When examining the effect of individual anti-HER2 treatment on OS after BM in multivariate analysis, use of both agents was associated with significantly greater survival benefit than no antiHER2 treatment (63\% risk reduction; HR, 0.37; 95\% CI 0.19-0.72), and a non-significant trend towards improved survival over either trastuzumab alone (HR, $0.51 ; 95 \%$ CI $0.25-1.01)$ or lapatinib alone (HR, 0.60; 95\% CI 0.27-1.31) (Table 5). In sensitivity analyses, treatment with both agents remained significantly associated with improved survival over no anti-HER2 treatment after relaxing the proportional hazards assumption for key confounders (HR, 0.35; 95\% CI 0.18-0.69; $P=0.002)$. All other comparisons also remained nearly identical, except for the HR comparing both agents to trastuzumab alone, which gained statistical significance (HR, 0.48; 95\% CI 0.24-0.96; $P=0.039$ ).

\section{DISCUSSION}

Patients with HER2-positive breast cancer are at increased risk of developing brain metastases (Bendell et al, 2003; Clayton et al, 2004; Shmueli et al, 2004; Stemmler et al, 2006; Park et al, 2009a). Anti-HER2 treatments have been shown to delay the development of brain metastases and prolong survival after BM in HER2positive breast cancer patients (Bartsch et al, 2007, 2012; Dawood et al, 2008; Park et al, 2009a, b; Le Scodan et al, 2011; Metro et al, 2011). However, most research has been limited to trastuzumab only and is primarily conducted in Western populations. In Asia, data on the use of anti-HER2 treatments in HER2-positive breast cancer patients with BM is limited. Our study provides a unique opportunity to understand the usage of trastuzumab and lapatinib among Asian HER2-positive breast cancer patients with brain metastases and the potential clinical role of anti-HER2 treatments on TTBM and survival after development of brain metastases in these patients.

The proportion of patients with leptomeningeal metastasis in this Asian HER2-positive breast cancer cohort (11\%) was similar to other HER2-positive breast cancer populations (9-19\%) (Bendell et al, 2003; Dawood et al, 2008; Park et al, 2009a, b) and higher than what has been observed for breast cancer patients in general (2-5\%) (DeAngelis et al, 2000, pp 867-874). These findings suggest that HER2-positive breast cancer patients are at increased risk of leptomeningeal metastasis and may have poorer prognosis. Closer surveillance with physicians' awareness is warranted for these patients.

We found that the majority of patients (93\%) in these Asian countries received radiotherapy as part of their care for BM, suggesting high level of compliance with recommended treatment guidelines and standard of care for BM (NCCN, 2011). However, 
Table I Patient characteristics

Anti-HER2 treatment after diagnosis of BM

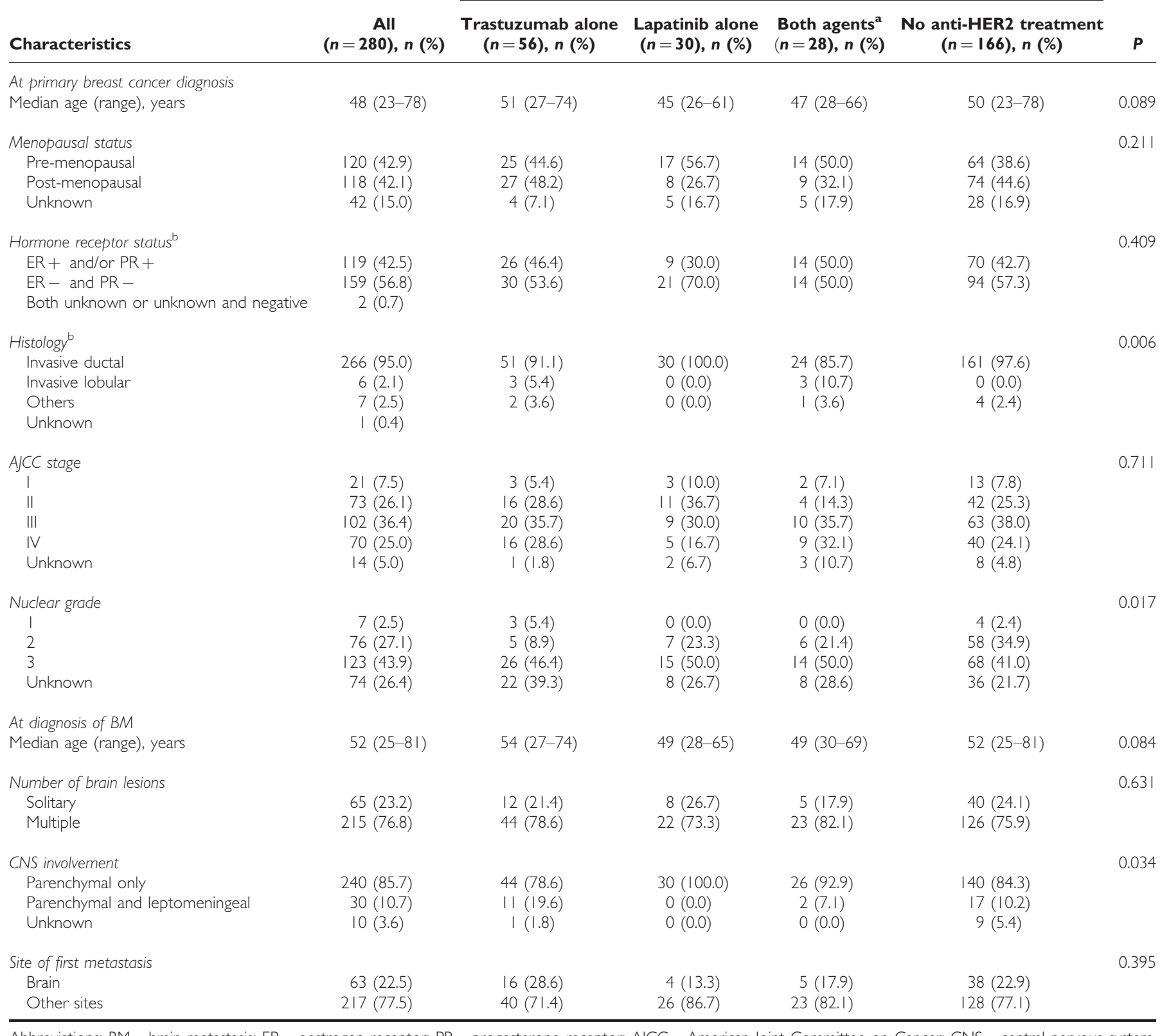

Abbreviations: $\mathrm{BM}=$ brain metastasis; $\mathrm{ER}=$ oestrogen receptor; $\mathrm{PR}=$ progesterone receptor; $\mathrm{AJCC}=$ American Joint Committee on Cancer; $\mathrm{CNS}=$ central nervous system.

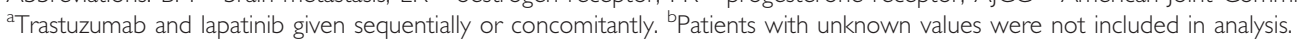

anti-HER2 treatment was not as uniformly utilised, ranging from $63 \%$ before BM to only $41 \%$ after BM. Of note, a quarter of patients (25\%) never received anti-HER2 treatment. Two other studies conducted in Korea also reported low usage of anti-HER2 treatment after BM. One study reported 33\% of anti-HER2 treatment usage after BM (Park et al, 2009b) and the other reported a decrease in anti-HER2 treatment usage from $71 \%$ before BM to $37 \%$ after BM (Park et al, 2009a). The pattern observed in Asia is in contrast to that in Western populations where there is no marked decrease in anti-HER2 treatment usage after BM (58-60\% before BM; $50-80 \%$ after BM) (Church et al, 2008; Eichler et al, 2008; Wolstenholme et al, 2008; Brufsky et al, 2011). The low usage of anti-HER2 treatment after BM observed in our Asian cohort may be largely related to the high costs associated with anti-HER2 treatment, especially in countries with no reimbursement. Further, discontinuation of anti-HER2 treatment upon the development of resistance to prior trastuzumab or lapatinib treatment may also partly explain the decline in use.

Our results showed that patients who received anti-HER2 treatment before BM, primarily trastuzumab alone, had 1.5 times significantly longer interval to the development of brain metastases than those who did not (33 vs 19 months). This concurs with the findings of previous studies, which reported a significant delay in the development of brain metastases with trastuzumab treatment in HER2-positive metastatic breast cancer (MBC) patients (Park et al, 2009a, b). 
BJC $\cap$

Several retrospective studies have demonstrated improved survival with trastuzumab treatment in HER2-positive breast cancer patients with brain metastases, with median survival ranging from 9 to 24 months (Bendell et al, 2003; Stemmler et al, 2006; Gori et al, 2007; Park et al, 2009b; Niwinska et al, 2010; Bartsch et al, 2012). The observed survival benefit has largely been attributed to control of the extracranial disease. Considering the promising activity of lapatinib against $\mathrm{BM}$ demonstrated in clinical studies (Boccardo et al, 2008; Lin et al, 2008, 2009; Ro et al, 2010; Sutherland et al, 2010; Bachelot et al, 2011; Lin et al, 2011), lapatinib may provide additional survival benefits to these patients.

In this Asian population, use of both anti-HER2 agents, primarily in a sequential manner, after BM demonstrated the greatest survival benefit (26 months vs 21 months for lapatinib alone vs 11 months for trastuzumab alone vs 6 months for no anti-

Table 2 Treatments

\begin{tabular}{|c|c|}
\hline Treatment & $\begin{array}{c}\text { All } \\
(n=280), n(\%)\end{array}$ \\
\hline \multicolumn{2}{|l|}{ Prior to diagnosis of $B M$} \\
\hline Hormonal therapy & $103(36.8)$ \\
\hline Chemotherapy & $252(90.0)$ \\
\hline Anti-HER2 treatment & $176(62.9)$ \\
\hline Other targeted therapy & $6(2.1)$ \\
\hline \multicolumn{2}{|l|}{ After diagnosis of $B M$} \\
\hline No treatment & $7(2.5)$ \\
\hline \multicolumn{2}{|l|}{ Local treatment } \\
\hline Radiotherapy ${ }^{\mathrm{a}}$ & $260(92.9)$ \\
\hline WBRT & $251(89.6)$ \\
\hline SRS or SRT & $32(11.4)$ \\
\hline Surgery & $35(12.5)$ \\
\hline Intrathecal treatment & II (3.9) \\
\hline \multicolumn{2}{|l|}{ Additional systemic treatment } \\
\hline Hormonal therapy & $34(12.1)$ \\
\hline Chemotherapy & $160(57.1)$ \\
\hline Anti-HER2 treatment & $114(40.7)$ \\
\hline Other targeted therapy & $5(1.8)$ \\
\hline \multicolumn{2}{|l|}{ Treatment combination } \\
\hline Radiotherapy ${ }^{\mathrm{a}}+$ surgery & $24(8.6)$ \\
\hline Radiotherapy ${ }^{\mathrm{a}}+$ surgery + chemotherapy & $19(6.8)$ \\
\hline Radiotherapy + chemotherapy & $153(54.6)$ \\
\hline 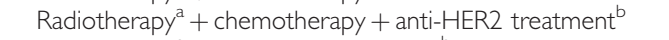 & $92(32.9)$ \\
\hline 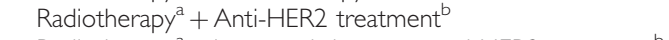 & $106(37.9)$ \\
\hline Radiotherapy ${ }^{a}+$ hormonal therapy + anti-HER2 treatment $^{b}$ & $17(6.1 \%)$ \\
\hline Surgery + chemotherapy & $25(8.9)$ \\
\hline
\end{tabular}

Abbreviations: $\mathrm{BM}=$ brain metastasis; $\mathrm{WBRT}=$ whole brain radiotherapy; $\mathrm{SRS}=$ stereotactic surgery; SRT = stereotactic therapy. ${ }^{a}$ Includes WBRT, SRS or SRT.

${ }^{b}$ Also includes other targeted therapy.
Anti-HER2 treatment and survival after brain metastases YS Yap et al

HER2 treatment). In the adjusted analysis, although nonsignificant, use of both anti-HER2 agents provided a $49 \%$ risk reduction over trastuzumab alone, and a $40 \%$ risk reduction over lapatinib alone. Recent observational studies in Western
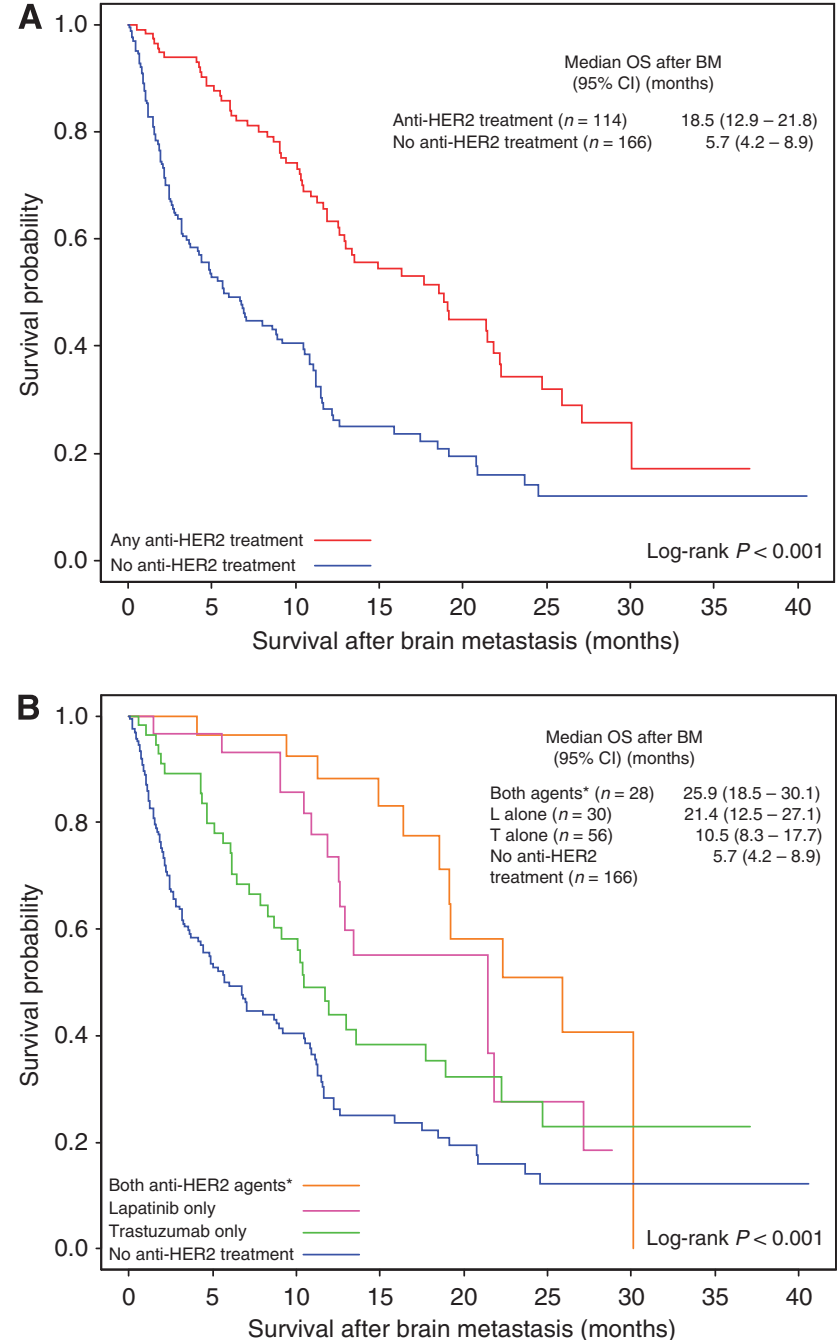

Figure 2 Overall survival (OS) after brain metastasis (BM) by anti-HER2 treatment received after diagnosis of brain metastasis (BM). (A) Anti-HER2 treatment vs no anti-HER2 treatment. Median OS after BM for all patients was 10.9 months $(95 \% \mathrm{Cl} 9.0-11.9)$. (B) Both agents vs lapatinib only vs trastuzumab only vs no anti-HER2 treatment. Median OS after BM for all patients was 10.9 months (95\% Cl 9.0-1 I.9). *Trastuzumab and lapatinib given sequentially or concomitantly.

Table 3

Anti-HER2 treatment patterns

Anti-HER2 treatment after diagnosis of BM

\begin{tabular}{lcccc}
$\begin{array}{l}\text { Anti-HER2 treatment } \\
\text { before diagnosis of BM }\end{array}$ & $\begin{array}{c}\text { Trastuzumab alone } \\
(\mathbf{n}=\mathbf{5 6}), \boldsymbol{n}(\mathbf{\%})\end{array}$ & $\begin{array}{c}\text { Lapatinib alone } \\
(\mathbf{n}=\mathbf{3 0}), \boldsymbol{n}(\%)\end{array}$ & $\begin{array}{c}\text { Both agents } \\
(\mathbf{n}=\mathbf{2 8}), \boldsymbol{n}(\%)\end{array}$ & $\begin{array}{c}\text { No anti-HER2 treatment } \\
(\boldsymbol{n}=\mathbf{1 6 6}), \boldsymbol{n}(\%)\end{array}$ \\
\hline Trastuzumab alone $(n=153)$ & $26(9.3)$ & $28(10.0)$ & $18(6.4)$ & $81(28.9)$ \\
Lapatinib alone $(n=2)$ & $0(0.0)$ & $0(0.0)$ & $0(0.0)$ & $2(0.7)$ \\
Both agents $(n=21)$ & $5(1.8)$ & $1(0.4)$ & $2(0.7)$ & $13(4.6)$ \\
No anti-HER2 treatment $(n=103)$ & $25(8.9)$ & $1(0.4)$ & $8(2.9)$ & $69(24.6)$ \\
\hline
\end{tabular}

Abbreviation: BM = brain metastasis. Note: Results are calculated as a percentage of the analysed population $(n=280){ }^{2}{ }^{2}$ Trastuzumab and lapatinib given sequentially (78.6\%; $n=22)$ or concomitantly $(21.4 \% ; n=6)$. 'Trastuzumab and lapatinib given sequentially $(85.7 \% ; n=18)$ or concomitantly $(\mid 4.3 \% ; n=3)$. 
Table 4 Results of Cox regression analyses for independent prognostic factors for overall survival (OS) after brain metastasis (BM)

\begin{tabular}{|c|c|c|c|c|}
\hline \multirow[b]{2}{*}{ Factor } & \multicolumn{2}{|c|}{ Univariate analysis } & \multicolumn{2}{|c|}{ Multivariate analysis } \\
\hline & Crude HR (95\% Cl) & $P^{\mathbf{a}}$ & Adjusted HR (95\% Cl) & $P^{\mathbf{a}}$ \\
\hline Menopausal status (pre- vs post-menopausal) & $0.59(0.43-0.81)$ & 0.003 & NS & NS \\
\hline Number of brain metastases lesions (multiple vs solitary) & $1.50(1.03-2.19)$ & 0.035 & $1.84(1.25-2.72)$ & 0.002 \\
\hline Leptomeningeal seeding ${ }^{c}$ (yes vs no) & $1.78(1.15-2.74)$ & 0.010 & NS & NS \\
\hline Chemotherapy after BM (yes vs no) & $0.24(0.18-0.33)$ & $<0.001$ & $0.27(0.19-0.39)$ & $<0.001$ \\
\hline
\end{tabular}

Abbreviations: $\mathrm{HR}=$ hazard ratio; $\mathrm{Cl}=$ confidence interval; $\mathrm{NS}=$ not significant; $\mathrm{BM}=$ brain metastasis; OS= overall survival. Note: The following factors were not significantly associated with $\mathrm{OS}$ after BM in univariate analysis: medical centre type, stage or nuclear grade of primary breast tumour at diagnosis, oestrogen and progesterone receptor status of primary breast tumour at diagnosis, duration between diagnosis of breast cancer and first metastases, brain as site of first metastasis, chemotherapy before diagnosis of BM, anti-HER2 treatment before diagnosis of BM, and hormonal therapy before diagnosis of BM. ${ }^{a} P$-value from the proportional hazards model. ${ }^{b}$ Variable modelled as a continuous variable. 'Patients with missing or unknown value(s) for this variable were excluded.

Table 5 Crude and adjusted association between anti-HER2 treatment received after diagnosis of brain metastasis (BM) and overall survival (OS) after BM

\begin{tabular}{lccr}
\hline Comparison & Crude HR (95\% Cl) & $\boldsymbol{P}^{\mathbf{a}}$ & Adjusted HR $\left.^{\mathbf{b}} \mathbf{( 9 5 \%} \mathbf{C l}\right)$ \\
\hline Both $^{c}$ vs no anti-HER2 & $0.24(0.13-0.44)$ & $<0.001$ & $0.37(0.19-0.72)$ \\
Both $^{c}$ vs trastuzumab alone & $0.41(0.21-0.81)$ & 0.011 & $0.51(0.25-1.01)$ \\
Both $^{c}$ vs lapatinib alone & $0.65(0.30-1.42)$ & 0.283 & $0.60(0.27-1.31)$ \\
Trastuzumab alone vs no anti-HER2 & $0.57(0.39-0.84)$ & 0.005 & $0.73(0.49-1.10)$ \\
Lapatinib alone vs no anti-HER2 & $0.36(0.21-0.62)$ & $<0.001$ & $0.62(0.35-1.11)$ \\
Lapatinib alone vs trastuzumab alone & $0.63(0.34-1.16)$ & 0.139 & 0.055 \\
\hline
\end{tabular}

Abbreviations: $\mathrm{HR}=$ hazard ratio; $\mathrm{Cl}=$ confidence interval; $\mathrm{BM}=$ brain metastasis. ${ }^{a} \mathrm{P}$-value from the proportional hazards model. ${ }^{\mathrm{b}}$ Model adjusted for age at diagnosis of $\mathrm{BM}$, number of brain metastases lesions, receipt of hormonal treatment after diagnosis of BM, and receipt of chemotherapy after diagnosis of BM. ${ }^{\circ}$ Trastuzumab and lapatinib given sequentially or concomitantly.

populations have also reported improved survival with the use of both anti-HER2 agents compared with trastuzumab alone. Metro et al (2011) demonstrated that patients treated with sequential combination of trastuzumab and lapatinib plus capecitabine $(n=30)$ had significantly longer survival compared with patients treated with trastuzumab-based treatments alone $(n=23)(28 v s 17$ months; $P=0.01)$. Bartsch et al (2012) showed that among 80 patients with brain metastases from HER2-positive breast cancer, use of trastuzumab and lapatinib, either sequentially or concomitantly, with or without chemotherapy was significantly associated with a $72 \%$ reduction in risk of death compared with trastuzumab-based treatment alone $(P=0.012)$.

Our results also concur with recent data from a large prospective study in the US that reported significantly longer survival after BM in HER2-positive MBC patients who received anti-HER2 treatment with or without chemotherapy $(72.5 \%$ trastuzumab alone; $27.5 \%$ trastuzumab and lapatinib) after BM than those who did not receive anti-HER2 treatment (median 17.5 vs 3.7 months; $P<0.001$ ) (Brufsky et al, 2011).

Our analysis showed that chemotherapy, hormonal therapy, and anti-HER2 treatment after BM were important predictors of prolonged survival, although the overlapping usage of these treatments may contribute to a confounding effect. Recent studies have also reported survival benefits associated with the use of systemic treatments in HER2-positive breast cancer patients with brain metastases (Park et al, 2009a; Braccini et al, 2011; Kim et al, 2012). These findings show the potential for systemic treatments in improving the outcome of breast cancer patients even after BM diagnosis.

These findings need to be interpreted within the limitations of the study design and sample size. First, this is a retrospective, nonrandomised study, and there is potential for imbalance in key prognostic factors between patients who received anti-HER2 treatment and those who did not, which may give rise to biased results. For instance, patients with better prognosis may be more likely to receive anti-HER2 treatment by virtue of living longer. Although we attempted to adjust for potential confounding factors that were known to be associated with treatment or survival, there is potential for unmeasured confounding by factors that were not collected. Nonetheless, our results were generally consistent with other retrospective studies. Second, as the sample size in each treatment group is small, further research with a larger number of patients is warranted to confirm our results. Next, there is the possibility that patients received sequential therapy with both antiHER2 agents by virtue of living longer, which may give rise to biased results. Also, patients who received both anti-HER2 agents sequentially may have a different treatment effect from those who received them concomitantly. However, our limited sample size does not allow these groups to be analysed separately. Future studies in a larger cohort are needed to confirm if there is a different treatment effect when both the drugs are used sequentially or concomitantly. Finally, as the majority of patients were from Korea and Singapore, the treatment patterns and outcomes of patients from other Asian countries merit further study.

In conclusion, there is limited usage of anti-HER2 treatment after detection of brain metastases among our Asian cohort of patients with HER2-positive breast cancer. Anti-HER2 treatment before BM, primarily trastuzumab alone, was associated with significantly longer time to the development of brain metastases. Anti-HER2 treatment after diagnosis of BM, along with local treatment and other systemic treatments, was associated with a survival benefit, especially when both trastuzumab and lapatinib were utilised. Our results support the role of continuing systemic treatments, including anti-HER 2 treatment, in improving survival even after development of brain metastases. The management 
strategy for HER2-positive brain metastases should incorporate the use of systemic treatments, including anti-HER2 treatment; clinical trials on anti-HER2 treatment in this setting will help to determine the optimal regimen.

\section{ACKNOWLEDGEMENTS}

This study was sponsored by GlaxoSmithKline, Brentford, United Kingdom. We would like to acknowledge the following investigators who have also contributed to the study-Indonesia: Dr Abdul Muthalib; Korea: Dr Joo Seop Chung, Dr Yu Jung Kim, Dr Hyuk Chan Kwon; Malaysia: Dr Biswa Mohan Biswal, Dr Adel Zaatar, and Thailand: Dr Surachat Chakrapee-Sirisuk, Dr Kanonporn Jaisathaporn, Dr Narongsak Kiatikajornthada, Dr Vicharn Lorvidhaya, Dr Pittayapoom Pattaranutaporn. We also thank Hui Hwa

\section{REFERENCES}

Altundag K, Altundag O, Atik MA, Morandi P, Gunduz M (2005) Rationale for the use of trastuzumab in patients with cerebral metastases who previously receive trastuzumab-based therapy for metastatic breast cancer. Breast 14: 425

Bachelot TD, Romieu G, Campone M, Dieras V, Cropet C, Roche HH, Jimenez M, Le Rhun E, Pierga J, Goncalves A, Leheurteur M, Domont J, Gutierrez M, Cure H, Ferrero J, Labbe C (2011) LANDSCAPE: an FNCLCC phase II study with lapatinib (L) and capecitabine (C) in patients with brain metastases (BM) from HER2-positive $(+)$ metastatic breast cancer (MBC) before whole-brain radiotherapy (WBR). J Clin Oncol 29(Suppl 15): 509

Bartsch R, Berghoff A, Pluschnig U, Bago-Horvath Z, Dubsky P, Rottenfusser A, DeVries C, Rudas M, Fitzal F, Dieckmann K, Mader RM, Gnant M, Zielinski CC, Steger GG (2012) Impact of anti-HER2 therapy on overall survival in HER2-overexpressing breast cancer patients with brain metastases. Br J Cancer 106: 25-31

Bartsch R, Rottenfusser A, Wenzel C, Dieckmann K, Pluschnig U, Altorjai G, Rudas M, Mader RM, Poetter R, Zielinski CC, Steger GG (2007) Trastuzumab prolongs overall survival in patients with brain metastases from Her2 positive breast cancer. J Neurooncol 85: 311-317

Bendell JC, Domchek SM, Burstein HJ, Harris L, Younger J, Kuter I, Bunnell C, Rue M, Gelman R, Winer E (2003) Central nervous system metastases in women who receive trastuzumab-based therapy for metastatic breast carcinoma. Cancer 97: 2972-2977

Boccardo F, Kaufman B, Baselga J, Dieras V, Link J, Casey MA, Fittipaldo A, Oliva C, Zembryki D, Rubin SD (2008) Evaluation of lapatinib (Lap) plus capecitabine (Cap) in patients with brain metastases (BM) from HER2 + breast cancer (BC) enrolled in the Lapatinib Expanded Access Program (LEAP) and French Authorisation Temporaire d'Utilisation (ATU). J Clin Oncol 26: 1094

Braccini AL, Azria D, Thezenas S, Chamorey E, Romieu G, Ferrero JM, Jacot W (2011) Prognostic factors of breast cancer brain metastases. Eur J Cancer 47(Suppl 1): S359 (poster 5098)

Brufsky AM, Mayer M, Rugo HS, Kaufman PA, Tan-Chiu E, Tripathy D, Tudor IC, Wang LI, Brammer MG, Shing M, Yood MU, Yardley DA (2011) Central nervous system metastases in patients with HER2-positive metastatic breast cancer: incidence, treatment, and survival in patients from registHER. Clin Cancer Res 17: 4834-4843

Cameron D, Casey M, Press M, Lindquist D, Pienkowski T, Romieu CG, Chan S, Jagiello-Gruszfeld A, Kaufman B, Crown J, Chan A, Campone M, Viens P, Davidson N, Gorbounova V, Raats JI, Skarlos D, Newstat B, Roychowdhury D, Paoletti P, Oliva C, Rubin S, Stein S, Geyer CE (2008) A phase III randomized comparison of lapatinib plus capecitabine versus capecitabine alone in women with advanced breast cancer that has progressed on trastuzumab: updated efficacy and biomarker analyses. Breast Cancer Res Treat 112: 533-543

Church DN, Modgil R, Guglani S, Bahl A, Hopkins K, Braybrooke JP, Blair P, Price CG (2008) Extended survival in women with brain metastases from HER2 overexpressing breast cancer. Am J Clin Oncol 31: 250-254

Clayton AJ, Danson S, Jolly S, Ryder WD, Burt PA, Stewart AL, Wilkinson PM, Welch RS, Magee B, Wilson G, Howell A, Wardley AM (2004) Incidence of cerebral metastases in patients treated with trastuzumab for metastatic breast cancer. Br J Cancer 91: 639-643
Choo for editorial assistance. C Khorprasert and DWY Wong have received research funding from GlaxoSmithKline.

\section{Conflict of interest}

YS Yap and N Sutandyo have received honoraria from GlaxoSmithKline. DWY Wong has received honoraria from Roche. M Kobayashi is an ex-employee of GlaxoSmithKline. SH Landis, EM Yeoh and $\mathrm{H}$ Moon are employees of GlaxoSmithKline. M Kobayashi, SH Landis, EM Yeoh and $\mathrm{H}$ Moon hold stock ownership in GlaxoSmithKline. J Ro has acted as an advisor and received honoraria from GlaxoSmithKline. The remaining authors declare no conflict of interest.

Supplementary Information accompanies the paper on British Journal of Cancer website (http://www.nature.com/bjc)

Dawood S, Broglio K, Esteva FJ, Ibrahim NK, Kau SW, Islam R, Aldape KD, Yu TK, Hortobagyi GN, Gonzalez-Angulo AM (2008) Defining prognosis for women with breast cancer and CNS metastases by HER2 status Ann Oncol 19: 1242-1248

DeAngelis L, Rogers L, Foley KM (2000) Leptomeningeal metastasis. In Diseases of the Breast, Harris JR (ed), pp 867-874. Williams and Wilkins: Philadelphia

DiStefano A, Yong Yap Y, Hortobagyi GN, Blumenschein GR (1979) The natural history of breast cancer patients with brain metastases. Cancer 44: 1913-1918

Eichler AF, Kuter I, Ryan P, Schapira L, Younger J, Henson JW (2008) Survival in patients with brain metastases from breast cancer: the importance of HER-2 status. Cancer 112: 2359-2367

Gori S, Rimondini S, De Angelis V, Colozza M, Bisagni G, Moretti G, Sidoni A, Basurto C, Aristei C, Anastasi P, Crino L (2007) Central nervous system metastases in HER-2 positive metastatic breast cancer patients treated with trastuzumab: incidence, survival, and risk factors. Oncologist 12: 766-773

Gril B, Palmieri D, Bronder JL, Herring JM, Vega-Valle E, Feigenbaum L, Liewehr DJ, Steinberg SM, Merino MJ, Rubin SD, Steeg PS (2008) Effect of lapatinib on the outgrowth of metastatic breast cancer cells to the brain. J Natl Cancer Inst 100: 1092-1103

Kim HJ, Im SA, Keam B, Kim YJ, Han SW, Kim TM, Oh DY, Kim JH, Lee SH, Chie EK, Han W, Kim DW, Kim TY, Noh DY, Heo DS, Park IA, Bang YJ, Ha SW (2012) Clinical outcome of central nervous system metastases from breast cancer: differences in survival depending on systemic treatment. J Neurooncol 106: 303-313

Le Scodan R, Jouanneau L, Massard C, Gutierrez M, Kirova Y, Cherel P, Gachet J, Labib A, Mouret-Fourme E (2011) Brain metastases from breast cancer: prognostic significance of HER-2 overexpression, effect of trastuzumab and cause of death. BMC Cancer 11: 395

Lichinitser M, Ganshina I, Zhukova L, Lud H, Meluzova O (2007) P26 HER2 overexpressed breast cancer and brain metastases. The Breast 16 (Suppl 1): S19 (abstract P26)

Lin NU, Carey LA, Liu MC, Younger J, Come SE, Ewend M, Harris GJ, Bullitt E, Van den Abbeele AD, Henson JW, Li X, Gelman R, Burstein HJ, Kasparian E, Kirsch DG, Crawford A, Hochberg F, Winer EP (2008) Phase II trial of lapatinib for brain metastases in patients with human epidermal growth factor receptor 2-positive breast cancer. J Clin Oncol 26: 1993-1999

Lin NU, Dieras V, Paul D, Lossignol D, Christodoulou C, Stemmler HJ, Roche H, Liu MC, Greil R, Ciruelos E, Loibl S, Gori S, Wardley A, Yardley D, Brufsky A, Blum JL, Rubin SD, Dharan B, Steplewski K, Zembryki D, Oliva C, Roychowdhury D, Paoletti P, Winer EP (2009) Multicenter phase II study of lapatinib in patients with brain metastases from HER2positive breast cancer. Clin Cancer Res 15: 1452-1459

Lin NU, Eierman W, Greil R, Campone M, Kaufman B, Steplewski K, Lane SR, Zembryki D, Rubin SD, Winer EP (2011) Randomized phase II study of lapatinib plus capecitabine or lapatinib plus topotecan for patients with HER2-positive breast cancer brain metastases. J Neurooncol 105: $613-620$

Metro G, Foglietta J, Russillo M, Stocchi L, Vidiri A, Giannarelli D, Crino L, Papaldo P, Mottolese M, Cognetti F, Fabi A, Gori S (2011) Clinical 
outcome of patients with brain metastases from HER2-positive breast cancer treated with lapatinib and capecitabine. Ann Oncol 22: 625-630

NCCN (2011) National Comprehensive Cancer Network Clinical Practice Guidelines in Oncology: Breast Cancer. Version 2.2011. http://www.nccn.org/professionals/physician_gls/pdf/breast.pdf (accessed November 2011)

Niwinska A, Tacikowska M, Murawska M (2010) The effect of early detection of occult brain metastases in HER2-positive breast cancer patients on survival and cause of death. Int J Radiat Oncol Biol Phys 77: 1134-1139

Park YH, Park MJ, Ji SH, Yi SY, Lim DH, Nam DH, Lee JI, Park W, Choi DH, Huh SJ, Ahn JS, Kang WK, Park K, Im YH (2009a) Trastuzumab treatment improves brain metastasis outcomes through control and durable prolongation of systemic extracranial disease in HER2-overexpressing breast cancer patients. $\mathrm{Br}$ J Cancer 100: 894-900

Park IH, Ro J, Lee KS, Nam BH, Kwon Y, Shin KH (2009b) Trastuzumab treatment beyond brain progression in HER2-positive metastatic breast cancer. Ann Oncol 20: 56-62

Pestalozzi BC, Brignoli S (2000) Trastuzumab in CSF. J Clin Oncol 18: 2349-2351

Ro J, Park S, Kim SB, Kim TY, Im YH, Rha SY, Chung JS, Moon H, Santillana S (2010) Clinical outcomes of brain metastasis by lapatinib (L) and capecitabine (C) in an open-label expanded access study among Korean patients with HER2 positive metastatic breast cancer. In 33rd Annual San Antonio Breast Cancer Symposium. (abstract P1-14-04); San Antonio, TX, USA

Shmueli E, Wigler N, Inbar M (2004) Central nervous system progression among patients with metastatic breast cancer responding to trastuzumab treatment. Eur J Cancer 40: 379-382

Slamon DJ, Leyland-Jones B, Shak S, Fuchs H, Paton V, Bajamonde A, Fleming T, Eiermann W, Wolter J, Pegram M, Baselga J, Norton L (2001)
Use of chemotherapy plus a monoclonal antibody against HER2 for metastatic breast cancer that overexpresses HER2. $N$ Engl J Med 344: 783-792

Stemmler HJ, Kahlert S, Siekiera W, Untch M, Heinrich B, Heinemann V (2006) Characteristics of patients with brain metastases receiving trastuzumab for HER2 overexpressing metastatic breast cancer. Breast 15: $219-225$

Sutherland S, Ashley S, Miles D, Chan S, Wardley A, Davidson N, Bhatti R, Shehata M, Nouras H, Camburn T, Johnston SR (2010) Treatment of HER2-positive metastatic breast cancer with lapatinib and capecitabine in the lapatinib expanded access programme, including efficacy in brain metastases-the UK experience. Br J Cancer 102: 995-1002

Vogel CL, Cobleigh MA, Tripathy D, Gutheil JC, Harris LN, Fehrenbacher L, Slamon DJ, Murphy M, Novotny WF, Burchmore M, Shak S, Stewart SJ, Press M (2002) Efficacy and safety of trastuzumab as a single agent in first-line treatment of HER2-overexpressing metastatic breast cancer. J Clin Oncol 20: 719-726

Wolstenholme V, Hawkins M, Ashley S, Tait D, Ross G (2008) HER2 significance and treatment outcomes after radiotherapy for brain metastases in breast cancer patients. Breast 17: 661-665

Yau T, Swanton C, Chua S, Sue A, Walsh G, Rostom A, Johnston SR, O'Brien ME, Smith IE (2006) Incidence, pattern and timing of brain metastases among patients with advanced breast cancer treated with trastuzumab. Acta Oncol 45: 196-201

cC) (9) This work is licensed under the Creative Commons C. $\mathrm{BY}$ NG SA Attribution-NonCommercial-Share Alike 3.0 Unported License. To view a copy of this license, visit http:// creativecommons.org/licenses/by-nc-sa/3.0/ 